\title{
Developmental changes in antioxidant enzymatic defences against oxidative stress in sheep placentomes
}

\author{
Catherine Garrel, Paul A Fowler ${ }^{1}$ and Kaïs H Al-Gubory ${ }^{2}$ \\ Laboratoire de Biologie du Stress Oxydant, Département de Biologie Intégrée, Centre Hospitalier Universitaire de Grenoble, 38043 Grenoble Cedex 9, France \\ ${ }^{1}$ Institute of Medical Sciences, Centre for Reproductive Endocrinology and Medicine, University of Aberdeen, Foresterhill, Aberdeen AB25 2ZD, UK \\ ${ }^{2}$ Institut National de la Recherche Agronomique (INRA), UMR 1198 Biologie du Développement et de la Reproduction, Département de Physiologie Animale, \\ 78352 Jouy-en-Josas Cedex, France \\ (Correspondence should be addressed to K H Al-Gubory; Email: kais.algubory@jouy.inra.fr)
}

\begin{abstract}
Early pregnancy is susceptible to oxidative stress, and thus characterisation of antioxidant systems and pro- and antiapoptotic pathways would improve understanding of placental development and function. We aimed, therefore, to determine the activities of the antioxidant enzymes, copper/zinc-superoxide dismutase (SOD1), manganeseSOD (SOD2), catalase (CAT), glutathione (GSH) peroxidase (GPX) and GSH reductase (GSR); and to quantify the expression of BAX and MCL1 proteins in relation to the developmental changes in antioxidant defences in sheep placentomes sampled on days 35, 55 and 80 of pregnancy. Placentome progesterone content was analyzed to determine steroidogenic capacity. Malondialdehyde (MDA) and protein carbonyl were quantified in placentomes as biomarkers of lipid peroxidation and protein damage respectively. Placentome tissues demonstrated significantly increased content of
\end{abstract}

progesterone and MDA at day 80 of pregnancy and protein carbonyl as early as day 50 of pregnancy. Progesterone and MDA contents were not different between days 35 and 55 of pregnancy. While SOD1 and CAT activities did not alter significantly, SOD2 activity decreased from days 35 to 55 . GPX activity increased from days 35 to 55 and increased further to day 80 of pregnancy. GSR activity increased from days 35 to 55 of pregnancy. BAX protein expression decreased, while MCL1 increased from days 35 to 55 and 80 of pregnancy. The increased GPX activity was associated with a decrease in the BAX/MCL1 protein expression ratio. Changes in the antioxidant enzymatic defences could be a part of placentome adaptation to reactive oxygen speciesinduced oxidative stress at specific early developmental stages of pregnancy.

Journal of Endocrinology (2010) 205, 107-116

\section{Introduction}

Maintaining a physiological equilibrium between intracellular levels of antioxidants and the production of reactive oxygen species (ROS) is crucial for the survival of the developing organisms. Tightly controlled ROS generation appears to be one of the central elements in the mechanisms involved in cell function, growth, differentiation and death (Valko et al. 2007). An increase in ROS generation beyond the ability of antioxidative protection, i.e. oxidative stress, potentially leads to cellular damage. Irreversible modification of cellular components, such as lipids, proteins and nucleic acids, by ROS leads to cell damage and dysfunction (Halliwell \& Gutteridge 1989). Mammalian cells have evolved a variety of antioxidant mechanisms to control ROS production and propagation (Fridovich 1999). Superoxide dismutases (SODs) are metalloenzymes that catalyze the dismutation of superoxide radical $\left(\mathrm{O}_{2}^{--}\right)$into hydrogen peroxide $\left(\mathrm{H}_{2} \mathrm{O}_{2}\right)$. Thus, they constitute the first enzymatic step that plays a vital role in the control of cellular $\mathrm{O}_{2}^{--}$ production. Two distinct isoforms of SOD have been identified in mammals. Copper-zinc containing SOD $(\mathrm{Cu}$, $\mathrm{Zn}-\mathrm{SOD}$ or SOD1) is a dimeric protein, essentially located in the cytoplasm. Manganese containing SOD (Mn-SOD or SOD2) is a homotetrameric protein, located in the mitochondria. Glutathione (GSH) peroxidases (GPXs) are located within the mitochondrial matrix and the cytoplasm, and catalase (CAT) found primarily within peroxisomes, both belong to the secondary defence mechanism by catalyzing the conversion of $\mathrm{H}_{2} \mathrm{O}_{2}$ to $\mathrm{H}_{2} \mathrm{O}$. GSH reductase (GSR) catalyzes GSH disulphide to reduced GSH, with NADPH as the reducing agent. GPX reduces $\mathrm{H}_{2} \mathrm{O}_{2}$ or other hydro peroxides using GSH as donor substrate. In the presence of iron, $\mathrm{H}_{2} \mathrm{O}_{2}$ and $\mathrm{O}_{2}^{--}$can interact in a Haber-Weiss reaction (Kehrer 2000) to generate highly toxic hydroxyl radical $\left(\mathrm{OH}^{*}\right)$. It follows that SOD1, SOD2, CAT, GPX and GSR represent co-ordinately operating defences against ROS propagation (Fig. 1). Studies of key antioxidant enzymatic activities are of utmost importance because they may indicate how tissue or organ might 


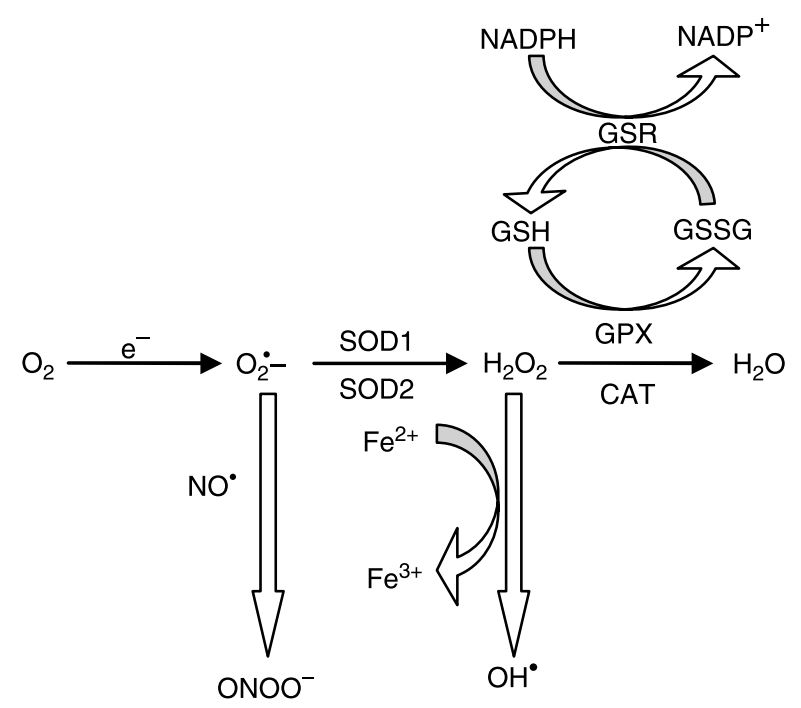

Figure 1 Schematic representation of the pathways producing reactive oxygen species (ROS) and key cellular antioxidant enzymatic systems controlling ROS production. Superoxide radical $\left(\mathrm{O}_{2}^{-}\right)$, hydrogen peroxide $\left(\mathrm{H}_{2} \mathrm{O}_{2}\right)$, nitric oxide $\left(\mathrm{NO} \mathrm{O}^{*}\right)$, peroxynitrite $\left(\mathrm{ONOO}^{-}\right)$, hydroxyl radical $\left(\mathrm{OH}^{-}\right)$, copper/zinc-superoxide dismutase (SOD1), manganese-SOD (SOD2), catalase (CAT), glutathione peroxidase (GPX), glutathione reductase (GSR), reduced glutathione (GSH), oxidized glutathione (GSSG), NADPH and oxidized $\mathrm{NADP}^{+}$.

respond to oxidative stress in oxidizing environment, such as during early placental development.

The effectiveness of antioxidant enzymes against ROS varies with the stage of human placental development (Sekiba \& Yoshioka 1979, Takehara et al. 1990, Qanungo et al. 1999, Jauniaux et al. 2000, Qanungo \& Mukherjea 2000). Oxidative stress during early human placental development (Myatt \& Cui 2004) is associated with human pregnancy-related disorders, such as preeclampsia, embryonic resorption, spontaneous abortion and intrauterine growth restriction (Agarwal \& Allamaneni 2004). Furthermore, oxidative stress alters human placenta development and may be a general underlying mechanism that links altered placental function to foetal programming (Myatt 2006). Therefore, understanding of factors that control ROS production during early placental development is essential to improving reproductive efficiency of humans and domestic animals. Although antioxidant enzymatic defences may play a role in antioxidative processes during human placental development, no attention has been paid to the ROS scavenging systems in placenta of domestic animals, leaving a gap in our knowledge about the importance of antioxidant mechanisms to control ROS production and oxidative stress during early placental development.

Ruminants (sheep, goat and cattle) have a cotyledonary placenta. The appropriate development and function of discrete areas of functional placentation, the placentomes, are central for optimal foetal growth and pregnancy outcomes. Rescue of the corpus luteum (CL) from cyclic luteal regression and maintenance of progesterone production are initially important events for the establishment of pregnancy in mammals. In both humans and sheep, the shift of progesterone production from the CL to the placenta occurs early in pregnancy, while the CL constitutes the principal source of progesterone throughout all or most of pregnancy in the mouse, rat, cat, rabbit, pig, goat, cow and horse (Ryan 1969). The early luteo-placental shift in progesterone production plays a crucial role in the maintenance of pregnancy beyond the lifespan of the CL in humans (Csapo et al. 1972) and sheep (Al-Gubory et al. 1999), allowing continued pre-natal development. Thus, compromised placental progesterone production is a potential risk factor for pregnancy outcomes in both species.

In early pregnancy, sheep placentomes undergo a series of morphological changes, which are characterized by cell proliferation and apoptosis (Riley et al. 2000). ROS-induced oxidative stress plays a role in apoptosis induction (Simon et al. 2000), at least in part, through changes in the expression of BCL-2-associated $\mathrm{X}$ protein, or BAX (Nakamura \& Sakamoto 2001) which was the first identified pro-apoptotic member of the BCL-2 protein family. BCL-2family proteins are key regulators of mitochondrial-related apoptosis pathways (Tsujimoto \& Shimizu 2000). Activities of SOD1 and GPX are lower (Wang \& Walsh 1996), and expression of BAX is higher in preeclamptic placenta than in normal full-term placenta (Cobellis et al. 2007). The antiapoptotic protein MCL1, a member of the BCL-2 protein family, preferentially inhibits BAX-induced mitochondrial cytochrome $\mathrm{C}$ release and apoptosis (Germain et al. 2008).

In order to improve understanding of the dynamics involved in early placental development and function in domestic animals, we aimed to investigate i) placentome steroidogenic capacity; ii) placentome content of malondialdehyde (MDA) and protein carbonyls as markers of lipid peroxidation and protein oxidation respectively; iii) the activities of key intracellular antioxidant enzymes (SOD1, SOD2, CAT, GPX and GSR) and iv) the expression of BAX and MCL1 proteins in relation to the developmental changes in antioxidant defences in sheep placentomes. In sheep, foetal chorionic villi interlock in predetermined regions of the maternal endometrium, known as caruncles, to form placentomes on and after the fourth week of pregnancy (Boshier 1969). Sheep placental cellular proliferation peaks between days 50 and 60 of pregnancy (Alexander 1964), and maximum placental weight is attained around day 80 of pregnancy (Ehrhardt \& Bell 1995). Placentomes (cotyledonary and caruncular tissues) were therefore sampled from singleton-bearing ewes at three physiologically significant stages of gestation, i.e. days 35,55 and 80 , coinciding with the period of early placentation, rapid placental growth and with the peak in placental weight. 


\section{Materials and Methods}

\section{Animals and tissue collection}

All procedures relating to care and use of animals were approved by the French Ministry of Agriculture according to the French regulation for animal experimentation (authorisation no. 78-34). Ewes of the Préalpes-du-Sud breed were treated for 14 days with intravaginal sponges containing $40 \mathrm{mg}$ fluorogestone acetate (Intervet, Angers, France) to synchronize oestrus. Immediately after removal of the sponges, each ewe received an i.m. injection of $400 \mathrm{IU}$ equine chorionic gonadotropin (Intervet). The ewes were mated at oestrus with fertile rams, twice at an interval of $12 \mathrm{~h}$. The ewes were killed at a local abattoir in accordance with protocols approved by the local institutional animal use committee. After killing, the reproductive tracts were collected and immediately transported to the laboratory. Placentomes (cotyledonary and caruncular tissues) were sampled from singleton-bearing ewes at days 35 and 55, coinciding with the period of early placentation (Boshier 1969) and rapid placental development (Alexander 1964), and at day 80, coinciding with the peak in placental weight (Ehrhardt \& Bell 1995). Ten representative placentomes were removed from the entire length of the two uterine horns of each pregnant ewe $(n=4$ ewes per gestational stage), snap frozen in liquid nitrogen and then stored at $-80{ }^{\circ} \mathrm{C}$ until processed for progesterone, MDA and protein carbonyl contents, the activities of SOD1, SOD2, CAT, GPX and GSR, and the expression of BAX and MCL1 proteins. The time that elapsed between the killing of the ewes and placentomes frozen in liquid nitrogen was $<10 \mathrm{~min}$.

\section{Extraction of progesterone from placentomes}

A simple extraction of progesterone from placentome tissues was performed as described previously for CL progesterone content (Marinelli et al. 2009), but instead of extracting progesterone with petroleum ether, it was extracted with ethanol. Briefly, tissues (wet weight $\sim 600 \mathrm{mg}$ ) were homogenized in $3 \mathrm{ml}$ of absolute ethanol $(200 \mathrm{mg} / \mathrm{ml}, \mathrm{w} / \mathrm{v})$, using an Ultra-Turrax homogenizer (Janke \& Kunkel IKA-Labortechnik, Staufen, Germany). Homogenates were centrifuged $(3500 \mathrm{~g})$ for $30 \mathrm{~min}$ at $4{ }^{\circ} \mathrm{C}$, and the ethanol extracts were then decanted into glass tubes. The organic phase was dried under a stream of nitrogen in a water bath at $37^{\circ} \mathrm{C}$. The dried extracts were dissolved in $0.5 \mathrm{ml}$ phosphate buffer $(0 \cdot 1 \mathrm{M}, \mathrm{pH} 7 \cdot 25)$ containing $0 \cdot 1 \%(\mathrm{wt} / \mathrm{v})$ gelatine, vortexed for $10 \mathrm{~min}$ at laboratory temperature and then the mixture assayed for progesterone. The recovery of tritiated progesterone in extracted placentome tissues was $82 \pm 2 \cdot 3$ (means \pm s.E.M.), and placentome progesterone contents were adjusted for recovery.

\section{Progesterone RIA}

Placentome ethanol extracts were analyzed for progesterone content in duplicate by a RIA as previously described
(Schanbacher 1979) and validated for sheep jugular venous plasma with slight modifications (Al-Gubory et al. 2006). Briefly, dextran-coated charcoal solution was used instead of polyethylene glycol for the separation of bound and free radioactivity. Tritiated progesterone (1,2,6,7-3H-progesterone, sp act $88 \mathrm{Ci} / \mathrm{mmol}$ ) was obtained from Amersham, and a specific anti-progesterone antibody was obtained from the Institut Pasteur (Paris, France). Hormone preparations, progesterone tracer and other reagents were diluted in $0 \cdot 1 \mathrm{M}$ PBS (pH 7.25). Tritiated P4 (3000 c.p.m.) in $100 \mu$ l buffer, $100 \mu \mathrm{l}$ progesterone antiserum (1/20000 dilution), $20 \mu \mathrm{l}$ progesterone standard, placentome extract samples, and $80 \mu \mathrm{l}$ buffer were dispensed into the assay tubes. After an initial 2-h incubation at laboratory temperature $\left(21^{\circ} \mathrm{C}\right)$ followed by 24-h incubation at $4{ }^{\circ} \mathrm{C}, 2 \cdot 2 \mathrm{ml}$ cold charcoal-dextran solution containing $0 \cdot 1 \%$ gelatine was added, and the tubes were centrifuged at $3000 \boldsymbol{g}$ for $45 \mathrm{~min}$. The supernatant was decanted into vials, and $3 \mathrm{ml}$ scintillation fluid (Scintillator Plus; Perkin-Elmer Life \& Analytical Sciences, Boston, MA, USA) was added to each vial. The radioactivity was counted in a Packard Tri-Carb Liquid Scintillation analyzer (model 2100 TR; Groningen, The Netherlands). Placentome content of progesterone was adjusted to picogram/milligram of tissue. To minimize assay variability, all placentome extract samples were analyzed in a single RIA. The limit of assay sensitivity was $0 \cdot 1 \mathrm{ng} / \mathrm{ml}$, and the intra-assay coefficient of variation was $<10 \%$.

\section{Antioxidant enzyme activity assays}

Placentome tissues corresponding to each stage of pregnancy from each ewe were homogenized separately in cold phosphate buffer $(50 \mathrm{mM}, \mathrm{pH} 7 \cdot 4)$, and then the homogenates were centrifuged at $15000 \mathrm{~g}$ for $30 \mathrm{~min}$ at $4{ }^{\circ} \mathrm{C}$. The resulting supernatant was used for determination of protein concentration (Lowry et al. 1951), MDA and carbonyl content and measurement of enzymatic activities. We used a standard SOD assay (Marklund \& Marklund 1974), which has been validated for different sheep reproductive tissues (Al-Gubory et al. 2004, 2005, 2006, 2008, Garrel et al. 2007). Total SOD activity was measured using the pyrogallol assay based on the competition between pyrogallol oxidation by $\mathrm{O}_{2}^{--}$and superoxide dismutation by SOD. SOD2 is encoded in the nuclear chromatin, synthesized as a precursor in the cytoplasm and imported posttranslationally into the mitochondrial matrix in its mature form (Wispe et al. 1989). The freeze-thaw approach results in mitochondrial release of large amounts of SOD2 into the cytosol (Jin et al. 2005). This approach was used for measurement of SOD2 activity in cytosol-enriched placentome fraction. We determined the enzymatic activity of SOD2 by assaying for SOD activity in the presence of sodium cyanide, which selectively inhibits SOD1 but not SOD2 (Jin et al. 2005). SOD1 activity was calculated by subtracting SOD2 activity from total SOD activity. The rate of auto-oxidation is taken from the increase in the absorbance at $420 \mathrm{~nm}$. One unit of SOD activity is 
defined as the amount of the enzyme required to inhibit the rate of pyrogallol auto-oxidation by 50\%. CAT activity was determined as described previously (Nzengue et al. 2008). Activity was assayed by determining the rate of decomposition of $\mathrm{H}_{2} \mathrm{O}_{2}$ by CAT in $10 \mathrm{mM}$ potassium phosphate buffer ( $\mathrm{pH}$ 7). The reaction rate was related to the amount of CAT present in the mixture. The rate of $\mathrm{H}_{2} \mathrm{O}_{2}$ decomposition by CAT was followed at $240 \mathrm{~nm}$. One unit was defined as the decomposition of $1 \mathrm{mmol}$ hydrogen peroxide per minute per milligram protein. GPX activity was measured using the GSR-NADPH method. Enzyme activity was determined by a coupled assay system in which oxidation of GSH was coupled to NADPH oxidation catalyzed by GSR. The rate of GSH oxidized by tertiary butyl hydroperoxide was evaluated by the decrease of NADPH in the presence of EDTA, excess reduced GSH and GSR. The rate of decrease in concentration of NADPH was recorded at $340 \mathrm{~nm}$. GPX activity was expressed in terms of nanometer of NADPH oxidized per minute per milligram protein. GSR activity was assayed by the standard method of NADPH oxidation. In this assay, oxidized GSH is reduced to GSH by GSR, which oxidizes NADPH to $\mathrm{NADP}^{+}$. NADPH consumption was determined at $340 \mathrm{~nm}$. Enzyme activity was expressed in terms of nanometer of NADPH oxidized per minute per milligram protein.

\section{Malondialdehyde measurement}

MDA, an end product of lipid peroxidation processes (Mukai \& Goldstein 1976), is frequently used as a biomarker of oxidative stress. The most widely used method for the determination of MDA in biological materials is based on its reaction with thiobarbituric acid (TBA). Reversed-phase HPLC techniques in which the MDA-TBA adducts are separated from interfering substances (Londero \& Lo Greco 1996) was used for determining MDA in placentome tissue homogenates. The breakdown product of 1,1,3,3-tetraethoxypropane (TEP) was used as standard. TEP undergoes hydrolysis to liberate stoichiometric amounts of MDA. Stock standard solution (480 $\mu \mathrm{l}$ of TEP in $100 \mathrm{ml}$ ethanol) was prepared, and this primary solution was diluted to the concentrations of $0,1,2,3$, 4,5 and $6 \mu \mathrm{M}$. Tissue extract aliquots or standards $(100 \mu \mathrm{l})$ were mixed with $750 \mu \mathrm{l}$ of $0.8 \% \mathrm{TBA}$. The tubes were placed in a water bath at $95^{\circ} \mathrm{C}$ for $1 \mathrm{~h}$, and then they were cooled. Samples were neutralized with methanol- $\mathrm{NaOH}$ mixture (pH 6). After centrifugation, $50 \mu \mathrm{l}$ of protein-free supernatant were chromatographed in the HPLC system. The column used for the separation was Adsorbosphere C18 (5 $\mu \mathrm{m}$ particle diameter, $250 \mathrm{~mm} \times 4.6 \mathrm{~mm}$ ID; Grace Davison Discovery Sciences Deerfield, IL, USA). The MDA-TBA adduct is eluted from the column with potassium dihydrogen phosphate buffer $(10 \mathrm{mM}, \mathrm{pH} 6 \cdot 0)$ - acetonitrile (17\%). The quantification of MDA derivative was established by comparing the absorption to the standard curve of MDA equivalents generated by acid-catalyzed hydrolysis of TEP as micromoles per gram tissue protein.

\section{Protein carbonyl measurement}

Protein oxidation is an oxidative stress marker (Zusterzeel et al. 2001), and the oxidation of proteins is often analyzed by measuring the protein-bound carbonyl groups. Protein carbonyl content was determined in placentome tissue homogenates as described previously (Levine et al. 1994). Briefly, $1 \mathrm{ml}$ 10\% trichloroacetic acid (TCA) and $1 \mathrm{ml} 10 \mathrm{mM}$ 2,4-dinitrophenylhydrazine solution was added to aliquots of placentome homogenates, and the mixture was vortexed and incubated at $37^{\circ} \mathrm{C}$ for $50 \mathrm{~min}$. Next, $1 \mathrm{ml}$ ice-cold TCA was added to the mixture. The pellet obtained after centrifugation at $3000 \mathrm{~g}$ for $10 \mathrm{~min}$ at $4{ }^{\circ} \mathrm{C}$ was washed three times with $1 \mathrm{ml}$ ethanol/ethyl acetate $(1: 1, \mathrm{v}: \mathrm{v})$. The last pellet was dissolved in $1 \mathrm{ml} 6 \mathrm{M}$ guanidine. After centrifugation at $12000 \mathrm{~g}$ for $10 \mathrm{~min}$, the absorbance of the supernatant was measured spectrophotometrically at $380 \mathrm{~nm}$ to quantify protein carbonyl, and its concentration was expressed as micromoles of carbonyl groups per gram of tissue protein.

\section{1-D gel electrophoresis and western blot}

Placentome tissues were processed for 1-D gel electrophoresis as described previously (Fowler et al. 2007a). Briefly, the frozen placentome tissues were blotted on filter paper and combined with lysis buffer ( $1 \mathrm{mg}$ wet tissue weight: $5 \mu \mathrm{l}$ lysis buffer) containing $0 \cdot 01 \mathrm{M}$ Tris-HCl, $\mathrm{pH} 7 \cdot 4,1 \mathrm{mM}$ EDTA, $8 \mathrm{M}$ urea, $0.05 \mathrm{M}$ dithiothreitol, $10 \%$ (v/v) glycerol, 5\% (v/v) NP40 and protease inhibitor cocktail (Roche Diagnostics). The tissues were placed in $2 \mathrm{ml}$ tubes containing a stainless steel ball, and all were simultaneously lysed (Tissue Lyser, $2 \mathrm{~min}$ at maximum; Qiagen Ltd). Supernatants were transferred to Eppendorf tubes and centrifuged at $50000 \mathrm{~g}$ for $20 \mathrm{~min}$ at $4{ }^{\circ} \mathrm{C}$. Protein content of the final supernatant containing the soluble cellular proteins had been determined (RC-DC assay, Bio-Rad Laboratories Ltd), and the placentome extracts were stored at $-80^{\circ} \mathrm{C}$. Individual lysates were electrophoresed (30 $\mu \mathrm{g}$ protein/lane) on 26-lane 1-DE 4-12\% Bis-Tris gels (Invitrogen Ltd) under reducing conditions (MOPS buffer, Invitrogen) and transferred to immobilon-FL membrane (Millipore Ltd, Watford, UK) as described previously (Fowler et al. 2007b). See Blue plus 2 molecular weight markers (Invitrogen) were electrophoresed in three lanes of every gel. The membranes were blocked (overnight at $4{ }^{\circ} \mathrm{C}$ ) with Odyssey Blocking Buffer (927-4000: LI-COR Biosciences Ltd, Cambridge, UK) and were incubated with primary antibodies (in blocking buffer) at $4{ }^{\circ} \mathrm{C}$ overnight: i) BAX (1:200: Santa-Cruz Biotechnology Inc., Santa Cruz, CA, USA, sc-493), ii) MCL1 (1:500: SantaCruz Biotechnology Inc., sc-95) combined with an anti- $\beta$ actin load control of differing species as appropriate (mouse 1:5000 AB6276; rabbit 1:10 000 AB8227, both Abcam Ltd, Cambridge, UK). The protein bands were visualized using an Odyssey infrared fluorescence imager (LI-COR), and the resulting electronic images were analyzed using Phoretix-1D 


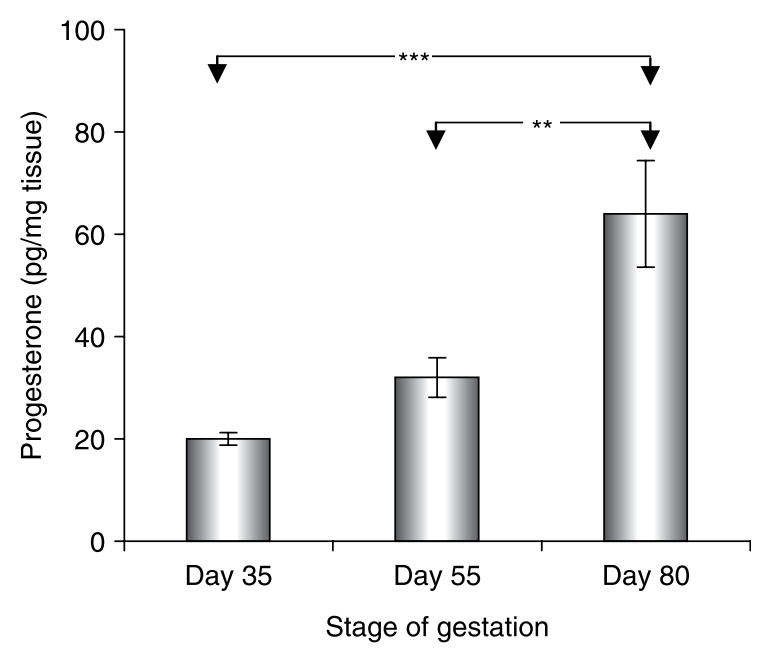

Figure 2 Progesterone contents in sheep placentomes $(n=10$ per ewe) collected from ewes at days 35 ( $n=4$ ewes), 55 ( $n=4$ ewes) and 80 ( $n=4$ ewes) of pregnancy showing significant increases in progesterone with gestational stages. Values are means \pm S.E.M. for the number of ewe used. ${ }^{* *} P<0 \cdot 01,{ }^{* * *} P<0 \cdot 001$.

advanced software (Nonlinear Dynamics Ltd, Newcastleupon-Tyne, UK) in order to determine the band volumes and molecular weights. This software calculates band volumes, based on constant lane width and automatic band selection, from the raw data of pixel area and intensity that are independent of operator-altered contrast or brightness. The specificity of the antibodies for the sheep proteins was tested by mixing the antibodies with blocking peptides, BAX (Santa Cruz Biotechnology; sc-493) at $5 \mu \mathrm{g} / \mathrm{ml}$ antibody solution and MCL1 (Santa Cruz Biotechnology; sc-958) at $2 \mu \mathrm{g} / \mathrm{ml}$ antibody solution, both incubated for $2 \mathrm{~h}$, prior to use. The blocking peptides prevented immunodetection of the relevant bands compared with incubation with antibody alone, and therefore the bands quantified were BAX and MCL1. There were no significant differences in $\beta$-actin band volumes between the gestational stages indicating the suitability of this load control for the present study.

\section{Statistical analysis}

The enzymatic activities, progesterone contents, MDA and carbonyl contents were analyzed by one-way ANOVA and the Newman-Keuls multiple comparison test (PRISM Graph Pad version 2; Graph Pad Software, San Diego, CA, USA). Western blot analyses were performed using JMP (version 5.1; Thomas Learning, London, UK). Normality of data distribution was tested with the Shapiro-Wilk test, and nonnormally distributed data were log-transformed prior to analysis. The band volumes, normalized relative to $\beta$-actin expression separate for each lane, were compared using oneway ANOVA. The acceptable level of significance was set at $P<0 \cdot 05$. Data are presented as the means \pm s.E.M.

\section{Results}

Progesterone content in placentome tissue homogenates (Fig. 2) rose steadily from days 35 to 80 of pregnancy $(P<0 \cdot 001)$, but although the contents of progesterone were significantly different between days 55 and $80(P<0 \cdot 01)$ and between days 35 and $80(P<0 \cdot 001)$ of pregnancy, progesterone contents between days 35 and 55 of pregnancy were not significantly different.

Protein carbonyl content in placentome tissue homogenates significantly increased from days 35 to $55(P<0 \cdot 05)$ and then remained relatively stable at that level at day 80 of pregnancy (Fig. 3a). MDA content in placentome tissue homogenates (Fig. 3b) significantly increased from days 35 to $80(P<0 \cdot 01)$ and from days 55 to $80(P<0 \cdot 001)$ of pregnancy. MDA content was not significantly different between days 35 and 55 of pregnancy.
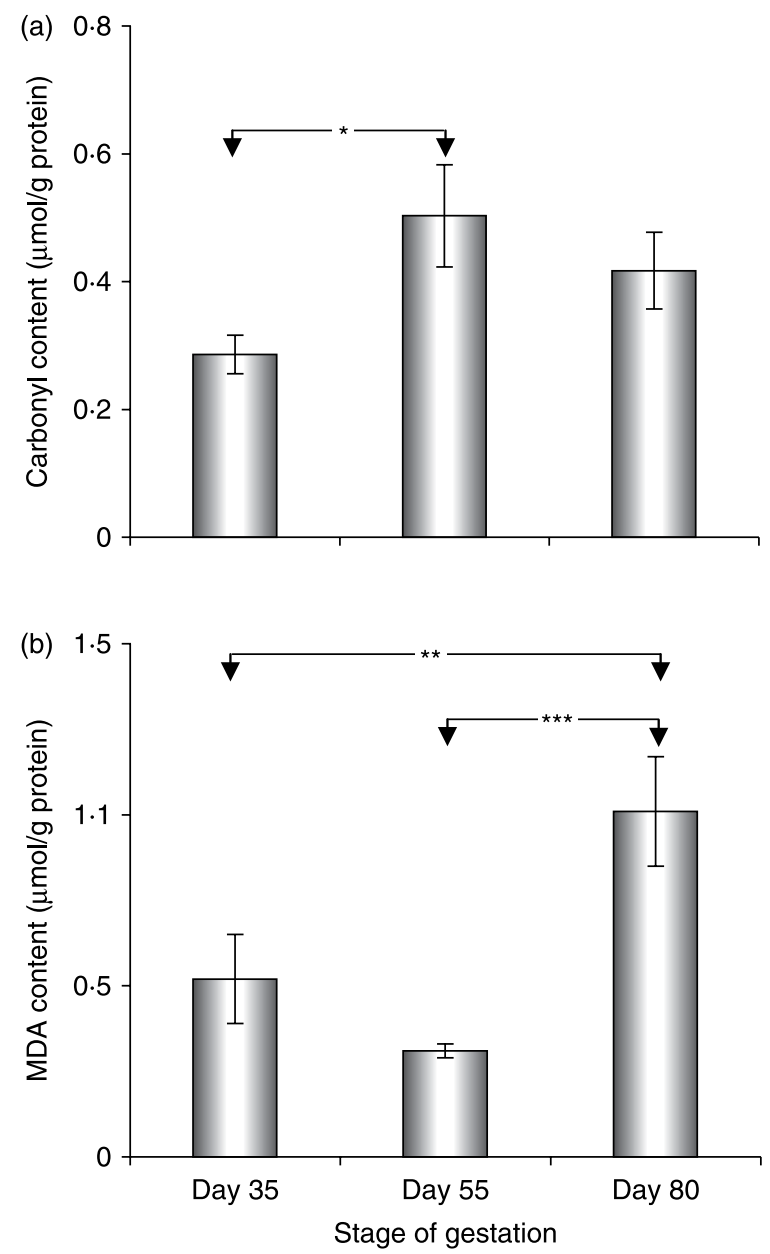

Figure 3 Protein carbonyl and malondialdehyde (MDA) contents in sheep placentomes ( $n=10$ per ewe) collected from ewes at days 35 ( $n=4$ ewes), 55 ( $n=4$ ewes) and 80 ( $n=4$ ewes) of pregnancy showing significant increases in (a) carbonyl and (b) MDA with gestational stages. Values are means \pm S.E.M. for the number of ewe used. $* P<0 \cdot 05, * * P<0 \cdot 01, * * * P<0 \cdot 001$.

Journal of Endocrinology (2010) 205, 107-116 
Enzymatic activities of SOD1, SOD2, CAT, GPX and GSR in sheep placentomes collected at days 35,55 and 80 of pregnancy are shown in Fig. 4a-e. The activity of SOD1 (Fig. 4a) was not different between any stages of the pregnancy examined. The activity of SOD2 (Fig. 4b) significantly decreased from days 35 to $55(P<0.05)$ and then remained relatively stable at that level at day 80 of pregnancy. The activity of CAT (Fig. 4c) was not different between any stages of the pregnancy examined. The activity of GPX (Fig. 4d) increased from days 35 to $55(P<0 \cdot 05)$ and increased further at day 80 of pregnancy $(P<0 \cdot 001$, days 80 vs $35 ; P<0 \cdot 01$, days 80 vs 55 ). The activity of GSR (Fig. 4e) peaked at day 55 , being significantly higher than that at days 35 and 80 of pregnancy $(P<0 \cdot 05)$.

Ovine BAX immunodetection was clear with a single band at $22 \mathrm{kDa}$, and ovine MCL1 immunodetection band was quantifiable at $40 \mathrm{kDa}$ (Fig. 5a). The expression of BAX protein (Fig. 5b) significantly decreased from days 35 to 55 $(P<0.05)$ and decreased further at day 80 of pregnancy $(P<0 \cdot 01$, days 80 vs 35$)$. The expression of MCL1 protein (Fig. $5 \mathrm{c}$ ) significantly increased from days 35 to 55 $(P<0.05)$ and from days 35 to $80(P<0.05)$ of pregnancy. To assess the balance between pro- and anti-apoptotic signalling, the BAX/MCL1 ratios were calculated (Fig. 5d), revealing a marked switch from pro-apoptotic to antiapoptotic signalling between days 35 and 55 and 80 of pregnancy $(P<0 \cdot 05)$.

\section{Discussion}

To the best of our knowledge, this is the first report of physiological changes in key antioxidant enzymatic pathways at specific early stages of placentome development in domestic animals. Interestingly, these changes coincide with the period of most rapid growth of the sheep placenta (Alexander 1964) and high steroidogenic activity (present study). Previous human studies have reported interesting but contradictory findings. Some of these studies showed an increase in SOD activity (Sekiba \& Yoshioka 1979, Takehara et al. 1990, Qanungo et al. 1999), whereas one study showed no changes (Jauniaux et al. 2000). However, all these studies only measured total SOD activity which is not informative of the changes in activity of cytosolic SOD1 and/or mitochondrial SOD2. This is important because mitochondria are the major sites of endogenous $\mathrm{O}_{2}^{--}$production (Wallace 2005). $\mathrm{O}_{2}^{--}$is converted to $\mathrm{H}_{2} \mathrm{O}_{2}$ by mitochondrial matrix SOD2, and in the presence of reduced transition metals, it can be converted to $\mathrm{OH}^{*}$ (Kehrer 2000), suggesting that the mitochondria are the prime target for ROS-induced oxidative damage (Wallace 2005). In addition, $\mathrm{H}_{2} \mathrm{O}_{2}$ is more stable than $\mathrm{O}_{2}^{-}$and can diffuse out of the mitochondria into the cytoplasm and the nucleus where it can leads to cell damage (Wallace 2005). Elevated activity of SOD2 would, in theory, promote $\mathrm{H}_{2} \mathrm{O}_{2}$ production and propagation of highly reactive $\mathrm{ROS}$ in the mitochondria and cytoplasm.
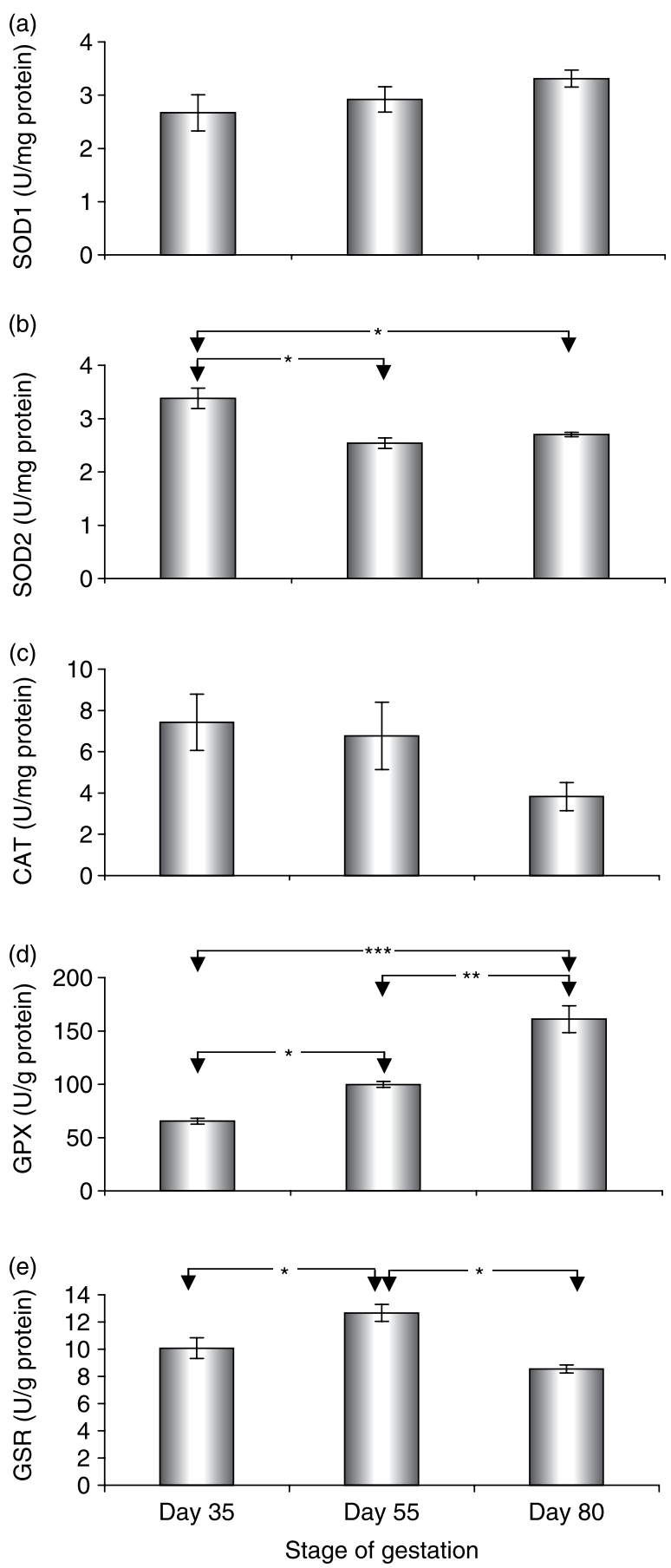

Figure 4 Changes in the activities of (a) SOD1, (b) SOD2, (c) CAT, (d) GPX and (e) GSR in sheep placentomes ( $n=10$ per ewe) collected from ewes at days 35 ( $n=4$ ewes), 55 ( $n=4$ ewes) and 80 ( $n=4$ ewes) of pregnancy showing significant alterations in SOD2, GPX and GSR with gestational stages. Values are means \pm s.E.M. for the number of ewe used. ${ }^{*} P<0 \cdot 05,{ }^{* *} P<0 \cdot 01,{ }^{* * *} P<0 \cdot 001$. 
(a)

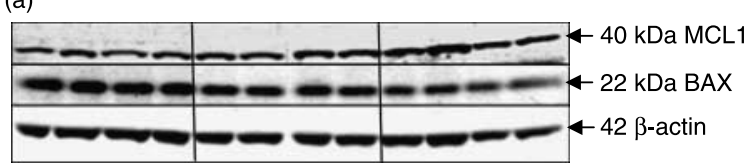

(b)

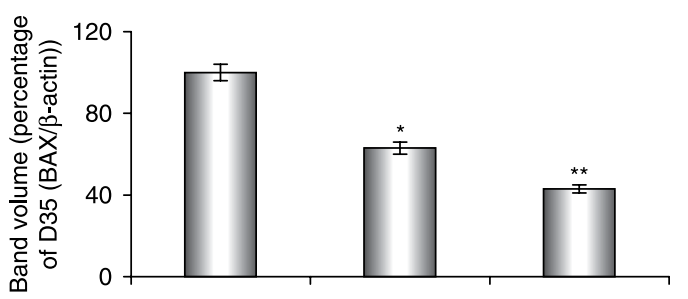

(c)
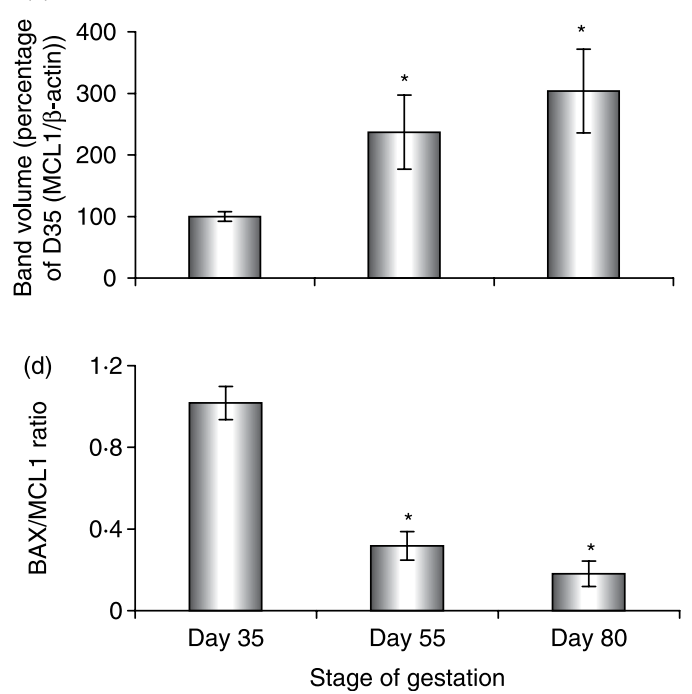

Figure 5 (a) Western blot (WB) analysis of MCL1 and BAX proteins expression in sheep placentomes $(n=10$ per ewe) collected from ewes at days 35 ( $n=4$ ewes), 55 ( $n=4$ ewes) and 80 ( $n=4$ ewes) of pregnancy showing (b) decreases in BAX, (c) increases in MCL1 and (d) decreases in the pro-/anti-apoptotic index (BAX/MCL1 ratio). Band volumes are means \pm S.E.M. normalized against $\beta$-actin load control values for the same lanes individually, for four ewes measured independently at each gestational stage. ${ }^{*} P<0 \cdot 05$, $* * P<0 \cdot 01$.

Furthermore, it may be assumed that elevated SOD2 activity may be directly harmful to the mitochondria through steady state $\mathrm{O}_{2}^{--}$production. Our results show that SOD1 activity in sheep placentomes did not alter across early pregnancy, whereas that of SOD2 significantly decreased from days 35 to 55 of pregnancy. The finding that GPX activity increased and that of SOD2 decreased in murine fibroblasts transfected with a SOD1 expression vector (Kelner \& Bagnell 1990) supports the hypothesis that a fine balance between antioxidant enzymes determines the cellular resistance to oxidative stress. The fact that $\mathrm{OH}^{*}$ can be formed by $\mathrm{H}_{2} \mathrm{O}_{2}$ metabolism via iron-catalyzed Fenton reaction and as by-products of lipid peroxidation, points to the importance of GPX within cells to remove $\mathrm{H}_{2} \mathrm{O}_{2}$ before it reacts with metal catalyst to form extremely toxic ROS. Under physiologically relevant conditions of sheep placental development between days 35 and 55 of pregnancy (present study), placentome cells may respond to oxidative stress by increasing GPX and GSR activities and decreasing SOD2 activity.

GPX has selenocysteine within its active site, and therefore, it is selenium dependent for antioxidant activity. The retention of the placenta in selenium-deficient cattle suggests a role for selenium-GPX in pregnancy outcomes (Eger et al. 1985). The increased GPX and GSR activity in sheep placentomes during early pregnancy (present study), also reported during human placental development for GSR (Qanungo et al. 1999) and GPX (Jauniaux et al. 2000) activities, is probably an important adaptive mechanism protecting the early developing placentomes against ROSmediated oxidative stress and cell damage. With respect to GPX activity measured in whole homogenate of human placental tissue, conflicting results have been reported, varying from unchanged (Takehara et al. 1990, Qanungo et al. 1999) or increased (Jauniaux et al. 2000) activity, as pregnancy advances. It may be that differences between these studies could be explained by experimental conditions, such as heterogeneity of whole placental tissues and variation in the timing of collection. GPX not only functions by removing $\mathrm{H}_{2} \mathrm{O}_{2}$ formed after the SOD-catalyzed dismutation reaction, but also detoxifies the lipid hydroperoxides (Hayes \& McLellan 1999). The efficiency of GPX may be attributable to the fact that it is located in both the cytoplasm and the mitochondrial matrix, and that it can utilize both $\mathrm{H}_{2} \mathrm{O}_{2}$ and lipid peroxides as substrates. Increased GPX activity during early pregnancy (present study) would protect the developing placentomes from ROS-induced cell damage, suggesting that GPX may be the major enzyme in defending against ROS attack within the sheep feto-placental unit.

In the present study, we demonstrated that BAX protein expression decreased, whereas that of MCL1 increased from days 35 to 55 and 80 of pregnancy in sheep placentomes. The BAX/MCL1 ratio decreased as pregnancy progresses, revealing a marked switch from pro-apoptotic to antiapoptotic signalling. It is interesting that the increased GPX activity we reported here in sheep placentomes during the first half of pregnancy was associated with a decrease in the BAX/MCL1 expression ratio. The induction of apoptosis in bovine luteal cells by downregulation of GPX (Nakamura et al. 2001) and the induction of apoptosis in cultured bovine luteal cells by simultaneous treatment with $\mathrm{H}_{2} \mathrm{O}_{2}$ and with a specific inhibitor of GPX (Nakamura \& Sakamoto 2001) suggest a role for $\mathrm{H}_{2} \mathrm{O}_{2}$ in $\mathrm{CL}$ apoptosis, at least in part through upregulation of BAX mRNA expression (Nakamura \& Sakamoto 2001). In vitro experiments also have shown that GPX overexpression in a human endothelial-like cell line downregulates BAX protein expression (Faucher et al. 2005). Considering these previous results, one can speculate that the increased GPX activity in sheep placentomes as pregnancy progresses (present study), and likely the maintained ability of 
placentome cells to scavenge $\mathrm{H}_{2} \mathrm{O}_{2}$, would contribute to the downregualtion of pro-apoptotic BAX protein expression and ultimately the BAX/MCL1 ratio. We suggest that the enhanced activity of GPX in sheep placentomes early in pregnancy may act as protective mechanism to prevent local tissue damage by directing $\mathrm{H}_{2} \mathrm{O}_{2}$ to form water and, thereby, preventing the production and propagation of potentially harmful ROS during feto-placental growth and development.

In the present study, MDA and carbonyl contents were measured in sheep placentomes during early developmental stages as being the end products of lipid peroxidation and protein damage respectively, and both as biomarkers of oxidative stress. Overall, the extent of placentome lipid peroxidation and protein oxidation increased markedly as gestation proceeds. MDA is a decomposition product of peroxidized polyunsaturated fatty acids (Mukai \& Goldstein 1976). Elevated lipid peroxide levels have also been reported to be greater in third trimester than first trimester human placental tissue (Diamant et al. 1980) and are found to be produced by the human placenta during uncomplicated pregnancy (Walsh \& Wang 1993).

The first and rate-limiting step in the synthesis of progesterone in all steroidogenic organs, including the placenta (Strauss et al. 1996), is the transfer of cholesterol from the outer mitochondrial membrane to the inner membrane where it is converted into pregnenolone by the enzyme cytochrome P-450 side-chain cleavage. It is well known that ROS are produced during enzyme reaction, particularly by the cytochrome P-450 family (Cross \& Jones 1991) and by the respiratory system of mitochondria (Cadenas \& Davies 2000), and thus, they are considered as a by-product of steroid synthesis. Increased placentome progesterone content on and after day 60 of pregnancy was accompanied by a corresponding increase in MDA content (present study). There is evidence that the inhibition of progesterone biosynthesis by a NADPH-dependent lipid peroxidation in human placental mitochondria is a consequence of cytochrome P-450 degradation due to lipid peroxidation (Klimek 1992). The increased MDA and carbonyl contents reported here in sheep placentomes support the hypothesis that pregnancy per se is a state of oxidative stress (Myatt \& Cui 2004) arising from high placental metabolic and steroidogenic activities.

Knowledge of placentome contribution to progesterone production during the first 2 months of pregnancy in domestic animals, including sheep, is still limited, and the antioxidative mechanisms involved in the control of placentome synthesis of progesterone during early pregnancy have not been elucidated. Moore et al. (1972) demonstrated the presence of small amounts of progesterone in the uterine vein blood of ewes between days 40 and 60 of pregnancy. In vitro studies have showed that foetal cotyledons from sheep placentomes have the potential for de novo synthesis of progesterone from pregnenolone as early as day 45 of pregnancy (Koligian \& Stormshak 1976). Placental production of progesterone has been shown to rise initially between days 50 and 70 of pregnancy in sheep (Ricketts \& Flint 1980). Taken together, these studies suggest that sheep placenta possess the capacity to synthesize and secrete progesterone prior to day 60 of gestation at which time the placenta begins producing progesterone in concentrations sufficient to maintain pregnancy. It was observed in the present in vivo study that ovine placentomes had already acquired appreciable steroidogenic capacity as early as day 35 of pregnancy. Increased placentome tissue progesterone contents on and after day 60 of pregnancy (present study), when the CL is no longer necessary to maintain pregnancy (Al-Gubory et al. 1999), indicates that the steroidogenic capacity of placentome cells increased as pregnancy advances. It was concluded that the interval between days 35 and 60 provides sufficient time to prepare the luteal-placental shift in progesterone production and secretion. ROS, particularly $\mathrm{H}_{2} \mathrm{O}_{2}$, have been shown to inhibit steroidogenesis by blocking cholesterol transport into mitochondria of rat luteal cells (Behrman \& Aten1991). In the present study, the increased enzymatic activity of GPX in sheep placentomes as pregnancy progresses, and consequently the increased ability of placentome cells to scavenge $\mathrm{H}_{2} \mathrm{O}_{2}$, would contribute to the maintenance of progesterone production.

In summary, we have demonstrated that the activities of the key antioxidant enzymes show major changes in sheep placentomes during early placental development. These data suggest that enhanced activities of GSH-related enzymes in placentomes during early pregnancy may act as protective mechanism against oxidative damage during early sheep fetoplacental development and growth. Adequate placental antioxidant status during early pregnancy could prevent and control those mechanisms and disorders induced by maternal environmental factors and associated oxidative stress that could lead to impairment of placental function, foetal growth and pregnancy outcomes.

\section{Declaration of interest}

The authors declare that there is no conflict of interest that could be perceived as prejudicing the impartiality of the research reported.

\section{Funding}

This research did not receive any specific grant from any funding agency in the public, commercial or not-for-profit sector.

\section{Acknowledgements}

The authors would like to thank Krawiec Angele, Catherine Mangournet, Sandra Grange, Christine Tozzoli, Cécile Mounioz (CHU Grenoble), Philippe Bolifraud and Christian Poirier (INRA, Jouy-en-Josas) and Margaret Fraser (University of Aberdeen) for their excellent technical assistance. The authors also thank the staff of the sheep sheds of Brouëssy and Jouy-en-Josas for outstanding technical help and sheep management. 


\section{References}

Agarwal A \& Allamaneni SSR 2004 Role of free radicals in female reproductive diseases and assisted reproduction. Reproductive Biomedicine Online 9 338-347.

Alexander G 1964 Studies on the placenta of the sheep (Ovis aries L). Placental size. Journal of Reproduction and Fertility 7 289-305.

Al-Gubory KH, Solari A \& Mirman B 1999 Effects of luteectomy on the maintenance of pregnancy, circulating progesterone concentrations and lambing performance in sheep. Reproduction, Fertility, and Development 11 317-322.

Al-Gubory KH, Bolifraud P, Germain G, Nicole A \& Ceballos-Picot I 2004 Antioxidant enzymatic defence systems in sheep corpus luteum throughout pregnancy. Reproduction 128 767-774.

Al-Gubory KH, Ceballos-Picot I, Nicole A, Bolifraud P, Germain G, Michaud M, Mayeur C \& Blachier F 2005 Changes in activities of superoxide dismutase, nitric oxide synthase, glutathione-dependent enzymes and the incidence of apoptosis in sheep corpus luteum during the estrous cycle. Biochimica et Biophysica Acta 1725 348-357.

Al-Gubory KH, Camous S, Germain G, Bolifraud P, Nicole A \& Ceballos-Picot I 2006 Reconsideration of the proposed luteotropic role of ovine placental lactogen in ewes: in vivo and in vitro studies. Journal of Endocrinology 188 559-568.

Al-Gubory KH, Bolifraud P \& Gareel C 2008 Regulation of key antioxidant enzymatic systems in the sheep endometrium by ovarian steroids. Endocrinology 149 4428-4434.

Behrman HR \& Aten RF 1991 Evidence that hydrogen peroxide blocks hormone-sensitive cholesterol transport into mitochondria of rat luteal cells. Endocrinology 128 2958-2966.

Boshier DP 1969 A histological and histochemical examination of implantation and early placentome formation in sheep. Journal of Reproduction and Fertility 19 51-61.

Cadenas E \& Davies KJ 2000 Mitochondrial free radical generation, oxidative stress, and aging. Free Radical Biology \& Medicine 29 222-230.

Cobellis L, De Falco M, Torella M, Trabucco E, Caprio F, Federico E, Manente L, Coppola G, Laforgia V, Cassandro R et al. 2007 Modulation of Bax expression in physiological and pathological human placentas throughout pregnancy. In Vivo 21 777-783.

Cross AR \& Jones OT 1991 Enzymic mechanisms of superoxide production. Biochimica et Biophysica Acta 1057 281-298.

Csapo AI, Pulkkinen MO, Ruttner B, Sauvage JP \& Wiest WG 1972 The significance of the human corpus luteum in pregnancy maintenance. I. Preliminary studies. American Journal of Obstetrics and Gynaecology 112 1061-1067.

Diamant S, Kissilevitz R \& Diamant Y 1980 Lipid peroxide in human placental tissue: general properties and influence of gestional age. Biology of Reproduction 23 776-781.

Eger S, Drori D, Kadoori I, Miller N \& Schindler H 1985 Effects of selenium and vitamin $\mathrm{E}$ on incidence of retained placenta. Journal of Dairy Science $\mathbf{6 8}$ 2119-2122.

Ehrhardt RA \& Bell AW 1995 Growth and metabolism of the ovine placenta during mid-gestation. Placenta 16 727-741.

Faucher K, Rabinovitch-Chable H, Cook-Moreau J, Barriere G, Sturtz F \& Rigaud M 2005 Overexpression of human GPX1 modify Bax to Bcl-2 apoptotic ratio in human endothelial cells. Molecular and Cellular Biochemistry 277 81-87.

Fowler PA, Tattum J, Bhattacharya S, Klonisch T, Hombach-Klonisch S, Gazvani R, Lea RG, Miller I, Simpson WG \& Cash P 2007a An investigation of the effects of endometriosis on the proteome of human eutopic endometrium: a heterogeneous tissue with a complex disease. Proteomics 7 130-142.

Fowler PA, Murray TJ, Abramovich DR, Haites NE, Cash P, Groome NP, Al-Qahtani A \& Lea RG 2007b Human fetal testis Leydig cell disruption by exposure to the pesticide dieldrin at low concentrations. Human Reproduction 22 2919-2927.

Fridovich I 1999 Fundamental aspects of reactive oxygen species, or what's the matter with oxygen? Annals of the New York Academy of Sciences 893 13-18.
Garrel C, Ceballos-Picot I, Germain G \& Al-Gubory KH 2007 Oxidative stress-inducible antioxidant adaptive response during prostaglandin $\mathrm{F}_{2 \alpha}$-induced luteal cell death in vivo. Free Radical Research 41 251-259.

Germain M, Milburn J \& Duronio V 2008 MCL-1 inhibits BAX in the absence of MCL-1/BAX interaction. Journal of Biological Chemistry 283 6384-6392.

Halliwell B \& Gutteridge JMC 1989 Protection against oxidants in biological systems: the superoxide theory of oxygen toxicity. In Free Radical in Biology and Medicine, pp 86-123. Eds B Halliwell \& JMC Gutteridge. Oxford: Clarendon Press.

Hayes JD \& McLellan LI 1999 Glutathione and glutathione-dependent enzymes represent a co-ordinately regulated defence against oxidative stress. Free Radical Research 31 273-300.

Jauniaux E, Watson AL, Hempstock J, Bao YP, Skepper JN \& Burton GJ 2000 Onset of maternal arterial blood flow and placental oxidative stress. A possible factor in human early pregnancy failure. American Journal of Pathology 157 2111-2122.

Jin ZQ, Zhou HZ, Cecchini G, Gray MO \& Karliner JS 2005 MnSOD in mouse heart: acute responses to ischemic preconditioning and ischemiareperfusion injury. American Journal of Physiology. Heart and Circulatory Physiology 288 H2986-H2994.

Kehrer JP 2000 The Haber-Weiss reaction and mechanisms of toxicity. Toxicology 149 43-50.

Kelner MJ \& Bagnell R 1990 Alteration of endogenous glutathione peroxidase, manganese superoxide dismutase, and glutathione transferase activity in cells transfected with a copper-zinc superoxide dismutase expression vector. Explanation for variations in paraquat resistance. Journal of Biological Chemistry 265 10872-10875.

Klimek J 1992 The influence of NADPH-dependent lipid peroxidation on the progesterone biosynthesis in human placental mitochondria. Journal of Steroid Biochemistry and Molecular Biology 42 729-736.

Koligian KB \& Stormshak F 1976 Progesterone synthesis by ovine fetal cotyledons in vitro. Journal of Animal Science 42 439-443.

Levine RL, Williams JA, Stadtman ER \& Shacter E 1994 Carbonyl assays for determination of oxidatively modified proteins. Methods in Enzymology 233 346-357.

Londero D \& Lo Greco P 1996 Automated high-performance liquid chromatographic separation with spectrofluorometric detection of a malondialdehyde-thiobarbituric acid adduct in plasma. Journal of Chromatography. A 729 207-210.

Lowry OH, Rosebrough NJ, Farr AL \& Randall RF 1951 Protein measurement with Folin phenol reagent. Journal of Biological Chemistry $193265-275$.

Marinelli L, Rota A, Carnier P, Da Dalt L \& Gabai G 2009 Factors affecting progesterone production in corpora lutea from pregnant and diestrous bitches. Animal Reproduction Science 114 289-300.

Marklund S \& Marklund G 1974 Involvement of the superoxide anion radical in the autoxidation of pyrogallol and a convenient assay for superoxide dismutase. European Journal of Biochemistry 47 469-474.

Moore NW, Barrett S \& Brown JB 1972 Progesterone concentrations in maternal and foetal blood plasma of ewes. Journal of Endocrinology $\mathbf{5 3}$ 187-194.

Mukai FH \& Goldstein BD 1976 Mutagenicity of malondialdehyde, a decomposition product of peroxidized polyunsaturated fatty acids. Science $191868-869$.

Myatt L 2006 Placental adaptive responses and fetal programming. Journal of Physiology 572 25-30.

Myatt L \& Cui X 2004 Oxidative stress in the placenta. Histochemistry and Cell Biology 122 369-382.

Nakamura T \& Sakamoto K 2001 Reactive oxygen species up-regulates cyclooxygenase-2, p53 and Bax mRNA expression in bovine luteal cells. Biochemical and Biophysical Research Communications 284 203-210.

Nakamura T, Ishigami T, Makino N \& Sakamoto K 2001 The down regulation of glutathione peroxidase causes bovine luteal cell apoptosis during structural luteolysis. Journal of Biochemistry 129 937-942. 
Nzengue Y, Steiman R, Garrel C, Lefêbvre E \& Guiraud P 2008 Oxidative stress and DNA damage induced by cadmium in the human keratinocyte $\mathrm{HaCaT}$ cell line: role of glutathione in the resistance to cadmium. Toxicology 243 193-206.

Qanungo S \& Mukherjea M 2000 Ontogenic profile of some antioxidants and lipid peroxidation in human placental and fetal tissues. Molecular and Cellular Biochemistry 215 11-19.

Qanungo S, Sen A \& Mukherjea M 1999 Antioxidant status and lipid peroxidation in human feto-placental unit. Clinica Chimica Acta 285 1-12.

Ricketts AP \& Flint AP 1980 Onset of synthesis of progesterone by ovine placenta. Journal of Endocrinology 8 337-347.

Riley SC, Webb CJ, Leask R, McCaig FM \& Howe DC 2000 Involvement of matrix metalloproteinases 2 and 9 , tissue inhibitor of metalloproteinases and apoptosis in tissue remodelling in the sheep placenta. Journal of Reproduction and Fertility 118 19-27.

Ryan KJ 1969 Theoretical basis for endocrine control of gestation - a comparative approach. In The Foeto-Placental Unit, pp 120-131.

Eds A Pécicle \& C Finzi. Amsterdam: Excerpta Medica Foundation.

Schanbacher BD 1979 Radioimmunoassay of ovine and bovine serum progesterone without extraction and chromatography. Endocrine Research Communications 6 265-277.

Sekiba K \& Yoshioka T 1979 Changes of lipid peroxidation and superoxide dismutase activity in the human placenta. American Journal of Obstetrics and Gynaecology 135 368-371.

Simon HU, Haj-Yehia A \& Levi-Schaffer F 2000 Role of reactive oxygen species (ROS) in apoptosis induction. Apoptosis 5 415-418.

Strauss JF III, Martinez F \& Kiriakidou M 1996 Placental steroid hormone synthesis: unique features and unanswered questions. Biology of Reproduction 54 303-311.
Takehara Y, Yoshioka T \& Sasaki J 1990 Changes in the levels of lipoperoxide and antioxidant factors in human placenta during gestation. Acta Medica Okayama 44 103-111.

Tsujimoto Y \& Shimizu S 2000 Bcl-2 family: life-or-death switch. FEBS Letters 466 6-10.

Valko M, Leiter D, Moncol J, Cronin MTD, Mazur M \& Telser J 2007 Free radicals and antioxidants in normal physiological functions and human disease. International Journal of Biochemistry and Cell Biology 39 44-84.

Wallace DC 2005 A mitochondrial paradigm of metabolic and degenerative diseases, aging, and cancer: a dawn for evolutionary medicine. Annual Review of Genetics 39 359-407.

Walsh SW \& Wang Y 1993 Secretion of lipid peroxides by the human placenta. American Journal of Obstetrics and Gynaecology 169 1462-1466.

Wang Y \& Walsh SW 1996 Antioxidant activities and mRNA expression of superoxide dismutase, catalase, and glutathione peroxidase in normal and preeclamptic placentas. Journal of the Society for Gynecologic Investigation 3 179-184.

Wispe JR, Clark JC, Burhans MS, Kropp KE, Korfhagen TR \& Whitsett JA 1989 Synthesis and processing of the precursor for human manganosuperoxide dismutase. Biochimica et Biophysica Acta 994 30-36.

Zusterzeel PL, Rütten H, Roelofs HM, Peters WH \& Steegers EA 2001 Protein carbonyls in decidua and placenta of pre-eclamptic women as markers for oxidative stress. Placenta 22 213-219.

Received in final form 5 January 2010

Accepted 22 January 2010

Made available online as an Accepted Preprint 22 January 2010 